\title{
Philip Morris' new scientific initiative: an analysis
}

In the fall of 2000, Philip Morris re-initiated an external research grants programme ("Philip Morris External Research Program", or PMERP), the first since the dissolution of the Council for Tobacco Research (CTR) and the Center for Indoor Air Research (CIAR). The ostensible purpose of the programme is to help develop cigarette designs "that might reduce the health risk of smoking". Internal company documents also indicate that Philip Morris urgently seeks to restore its scientific "credibility", as part of a "new openness" in relation to the external community. The structure of the review panel-a cohort of external peer reviewers, a science advisory board, and an internal, anonymous review and approvals committee-is nearly identical to that of the CIAR. The majority of the named reviewers have had previous affiliation with the tobacco industry either as reviewers or grantees, but only a minority have done research directly on tobacco or smoking. The programmatic substance of the PMERP could be interpreted as soliciting exculpatory evidence with respect to smoking and exposure to smoke. We remain sceptical about the scientific integrity of PMERP.

(Tobacco Control 2001;10:247-252)

Keywords: Philip Morris; scientific credibility; tobacco industry

In the fall of 2000, the "Philip Morris External Research Program" (PMERP), an initiative of Philip Morris' Worldwide Scientific Affairs (WSA), circulated a document titled "Request for Applications [-] 2000 Research Focus". This was the first solicitation of tobacco industry funded research proposals since the dissolution of both the Council for Tobacco Research (CTR) and the Center for Indoor Air Research (CIAR) under the terms of the Master Settlement Agreement (MSA) with the US attorneys general. ${ }^{1}$ Whereas the earlier two research bodies had support from several tobacco companies, Philip Morris (PM) is the sole, visible funder of the PMERP.

The request for applications has three main features: description of the "Research focus", the programme's review process, and a list of 105 named "peer reviewers". In this paper we examine PM documents related to funding of tobacco research; the organisational structure and proposed research focus of PMERP; and the tobacco related research expertise of PMERP listed reviewers.
Philip Morris seeks credibility and scientific integrity

An April 1998 document lists the rationale for PM's Worldwide Scientific Affairs unit. Under the title "Reason to be", the text notes that, among other justifications, WSA exists "to provide scientific evidence to encourage accommodation of smoker's right to smoke" and to "contribute towards rebuilding the company's scientific credibility". ${ }^{2}$

A more recent WSA document lists specific strategies to attain "credibility": "Establish a worldwide list of universities that have either private research institutions attached, or that are in close cooperation with such institutions ... Establish a compendium of possibilities to give visual signs of the 'new openness' (coverage of anti conferences, sending industry papers to anti journals, seeking discussions in the public)."”

Another 1999 document asks: "How will we improve our credibility within the scientific community in order to ensure that a balanced view is taken on smoking and health science? [emphasis in original]."

It is likely that PMERP is one of many steps PM has taken to use science to strengthen its legal and financial positions in the face of growing anti-industry pressure from around the world. The "new openness" in industry sponsored research may reasonably be viewed as a reaction to the damning disclosures from industry documents made available to the public through the past several years' litigation. $^{5}$

Three essential questions need to be asked concerning PMERP: Will the funded research provide real scientific advances, or will it co-opt the scientific community into providing a "balanced view" of smoking and health issues? Will PM seek good science or exculpatory science? And, finally, why should we trust PM given that their past support of scientific research was done primarily to support a legal and public relations agenda, not to answer compelling scientific questions about tobacco and health?

The "Research focus"

The stated purposes of the PMERP include helping "address the concerns of the public health community regarding cigarette smoking" and enabling "PM to continue its pursuit of product modification(s) or new product design(s) that might reduce the health risk of smoking". The January 1999 WSA draft strategic plan laid out the range of "scientific and technical issues of greatest importance to the company" [emphasis in original], such as methodology (epidemiology, study design, risk assessment), smoking and health, 
smoking behaviour, and nicotine. PMERP follows these recommendations closely, but does not directly address some of the other listed scientific issues such as smoke constituents, smoke behaviour and compensation, product integrity, tobacco chemistry, and cigarette design. ${ }^{4}$

The four major sets of topics that comprise the "Research focus" include:

- exposure/biomarkers/dosimetry

- epidemiological research

- clinical and model systems research

- tobacco smoke and smoking behaviour

Under "exposure/biomarkers/dosimetry", the text notes, unexceptionally: "Exposure assessment is a necessary component in the design of reliable studies to determine health consequences of exposures . . . Exposure estimates classically are obtained from self-reports, area and personal monitoring, and biological monitoring with biomarkers... Biomarkers may be useful in assessing exposure as well as effects." In the past, however, industry studies using body monitors have notoriously underestimated cumulative dosage from second hand smoke. ${ }^{78}$ It is troubling that, in sponsoring such studies, the PMERP may effectively be the only major source of funding for exposure research on environmental tobacco smoke in the USA. The US Environmental Protection Agency (EPA) left the field of environmental tobacco smoke (ETS) research following budget negotiations with Congress, in exchange for release of the 1992 report on second hand smoke (James Repace, former EPA researcher, and Michele Bloch, National Cancer Institute, personal communications, January 2001). No other non-industry agency, to our knowledge, currently makes dosimetry a research focus priority.

"Epidemiological research" is subdivided into: cancer of all sites; cardiovascular diseases (CVD); respiratory disease, including asthma and chronic obstructive pulmonary disease (COPD); and reproductive, maternal and placental effects. In the introduction it is stated: "Methodologically, epidemiologic studies require accurate estimates of exposure and must be designed to have the power and sensitivity necessary to test the hypothesis."

The industry has long held the view that, with respect to second hand smoke, the epidemiological evidence of harm to non-smokers is either insufficient or is confounded by either environmental or other "lifestyle" factors, or both. ${ }^{9}$

Further, the text states that: “ . . .a number of inhalable agents such as tobacco smoke and other combustion mixtures, particulate matters, and oxidants have been implicated in the etiology or development of disease in human populations."

It is quite conceivable that by mentioning tobacco smoke in the same breath as "other" unspecified combustion mixtures, the PMERP is attempting to dilute the perceived role of passive smoke in disease causation.

A regulatory agency typically seeks to protect public health by taking into account the preponderance of evidence (cellular toxicology, animal exposures, human epidemiology) in assessing the risk posed by a substance, particularly in the case of agents acting at low doses over an extended period of time. By contrast, however, the tobacco industry criticised the US EPA report, the US Occupational Safety and Health Administration (OSHA) rules proposed for workplace smoking, and the International Agency for Research on Cancer (IARC) study on second hand smoke, demanding precise, biomarker evidence in humans but rejecting nicotine and cotinine as appropriate biomarkers. ${ }^{9-11}$ PM does not accept that second hand smoke is a causal hazard to health, a position similar to the one it held on direct smoking until its public admission in October 2000. ${ }^{12}$

With respect to cancer, PMERP states: "Epidemiological research is needed to identify external and internal risk factors for the development of cancer of all sites as well as to characterize the independence or confounding potential of factors operating within complex multi-path biological systems." For decades the industry has asserted that along with several confounding variables such as diet and lifestyle, tobacco was merely another "risk factor" for cancer. It was only in October 2000 that PM unequivocally acknowledged that tobacco smoking causes cancer, and by known biological mechanisms. ${ }^{12}$ The PMERP request for proposals seems to suggest further research on "confounding" variables that might, at least partially, exculpate tobacco-a scientific stance critical to the defence in current and future lawsuits against the industry.

The text acknowledges that cardiovascular disease "represents the largest, single contribution to morbidity and mortality in developed countries". Notably, the tobacco industry, in its attack on worldwide tobacco control efforts, insists that developing countries do not face the same morbidity and mortality from tobacco related diseases. ${ }^{13-16}$ This is despite World Health Organization predictions that by 2020 tobacco attributable deaths worldwide will correspond to $12.3 \%$ of all deathssurpassing diarrhoeal diseases, perinatal diseases, and tuberculosis - and that by 2030 $70 \%$ of tobacco related deaths will occur in the developing world. ${ }^{17}$

As for "reproductive health", the text suggests that there may be some substances in "complex mixtures such as tobacco smoke [which] have been implicated in the causation of reproductive and developmental health effects such as low birth weight". This may be taken to suggest that some components in the complex mixture are the actual cause of low birth weight and, if removed, could conceivably allow pregnant women to continue smoking without placing their fetuses at risk, congruent with the industry's research on product modification.

Similarly, in the "clinical and model systems research" section, it is implied that if the precise interactions of agent (smoke) and host were understood, health risks could be reduced by modifying one or better equipping the 
other. The document indicates a particular interest in research proposals that emphasise host susceptibility, genetic factors, and molecular and cellular mechanisms of disease. For cardiovascular diseases, proposals to study cellular, biochemical, and molecular mechanisms and "relevant smoke constituents" are welcomed, as these would lead to an examination of the physiological chain of events by which inhaling "particle and vapor phase constituents" induces a generalised inflammatory response as the proximal cause of a "coronary event".

This section holds the most interest for those who believe that a safer cigarette would be possible if only the "relevant smoke constituents" of tobacco's "complex mixture", as they relate to the aetiology of cancer, cardiovascular disease, respiratory diseases, and other illnesses, could be identified and eliminated.

The final section, "tobacco smoke and smoking behavior", principally requests research proposals on topics like "the role of nicotine and/or other substances as determinants of smoke exposure" and "brain activity measured differentially with modern imaging techniques, in order to understand neural processes occurring before, during and after smoking". It also calls for studies to characterise "pharmacologically active constituents of tobacco smoke ..." other than nicotine. No mention is made of research on how to conquer nicotine addiction.

The PMERP research focus therefore describes a detailed approach to understanding tobacco's role in human disease-one not much different from that of the US National Cancer Institute's (NCI) Tobacco Research Implementation Plan, published in $1998 .^{18}$ However, the NCI's research agenda is more comprehensive in that it also includes research on cessation, community level interventions, surveillance, and policy. The plan's biomedical research is just getting underway, but does not yet include work on second hand smoke. What is more important to ask is whether a tobacco company can be relied upon to sponsor, promote, and disseminate credible study findings. In the past, tobacco industry sponsored research was used to advance the industry's political agenda and has not always passed the test of scientific integrity. ${ }^{19}$ Whether or not the research generated by PMERP will be different, remains to be seen.

"Research and review process overview" PMERP's structure is the same as that of the now defunct CIAR. Indeed, the texts of the 1998 CIAR request for applications and of the PMERP request for applications are almost identical, except that CIAR's focus was on problems related to indoor air quality while PMERP's mandate is substantially broader. ${ }^{20}$

In both cases, there is a science advisory board (SAB) and the PMERP document lists six persons as SAB members. All are well published senior scientists, and three of them have had past associations with CIAR. ${ }^{20-23}$ The SAB makes recommendations for funding based on the evaluation of the peer reviewers. A concern is that final funding decisions, both at the former CIAR and at PMERP, rest with the tobacco industry, raising questions regarding the integrity and independence of the grant process. This issue was in fact raised by Helmut Reif, director of science and technology at PM's research and development unit in Neuchatel, Switzerland, when commenting on the proposal for the creation of a new corporation to fund indoor air quality research, in the wake of CIAR's closing. Regarding the authority of a board of directors to have final approval of funding, Reif stated: "Here, I fear, we have the same disputable situation as with CIAR, that the SAB wants or does not want something, decides after lengthy discussions, and finally is overruled by the Board of Directors? Can we ensure that the scientific opinion of the SAB would carry some weight? Otherwise they might feel bad and possibly quit." ${ }^{24}$

The members of the PM scientific research review committee, which has the final funding authority, are not identified in the PMERP application document, but their role is to assure the company that all funded studies meet "the highest scientific, ethical, and legal standards and serve relevant business needs...." [emphasis added]. The January 1999 draft of WSA's strategic plan stated that one of the WSA's roles was to: “. . . manage the Scientific Research Review Committee's review and approval of all tobacco, smoke and/or smoking related scientific studies conducted or funded by Philip Morris Companies."

Similarly, a body known as the "Research management group" is charged with managing PMERP. It has the same address as CIAR in Maryland, USA, and former CIAR director Max Eisenberg is the designated contact person for all inquiries about the programme.

\section{Profile of the peer reviewers}

It is impossible to determine which reviewers PM will actually select. But PM's publication of the names and affiliations of 105 potential reviewers is revealing. During the month of November 2000, we searched Medline to count the number of papers authored or co-authored by each individual (see below ${ }^{\dagger}$, and computed the ratio of tobacco-related articles through the $\mathrm{MeSH}$ headings (using the following terms: smok ${ }^{\star}$, nicotine, tobacco, indoor air, ETS). We also used Internet search engines Monster Crawler, Yahoo! and Google to confirm each peer reviewer's name, institution, department and, where possible, area(s) of expertise/specialty. Additionally, we searched on the potential reviewers' names in the databases of the tobacco industry documents that are available on the Internet. By this method, we were able to ascertain previous connections between peer reviewers and industry sponsored research efforts. Tables 1 and 2 summarise our findings. ( ${ }^{\dagger}$ Our total count is a close estimate as some persons with common names have namesakes writing in completely different specialties, and a thorough effort has been made to screen these out. A handful of reviewers co-authored papers 
Table 1 Peer reviewers'profile

\begin{tabular}{|c|c|}
\hline Characteristics & Number (\%) \\
\hline \multicolumn{2}{|l|}{ Degree } \\
\hline $\mathrm{PhD}$ & $82(78)$ \\
\hline MD & $19^{\star}(18)$ \\
\hline Other & $4(4)$ \\
\hline \multicolumn{2}{|l|}{ Affiliation } \\
\hline University & $79(75)$ \\
\hline US EPA & $6+(6)$ \\
\hline Retired PM scientist & $3(3)$ \\
\hline Other & $17 \ddagger(16)$ \\
\hline \multicolumn{2}{|l|}{ Specialty } \\
\hline Air pollutant and air quality research & $46(44)$ \\
\hline Asthma/immunology/allergy & $17(15)$ \\
\hline Pulmonary and respiratory diseases & $13(12)$ \\
\hline Molecular and tumour toxicology & $7(6)$ \\
\hline Alzheimer's disease & $4(4)$ \\
\hline Drug metabolism & $4 \S(4)$ \\
\hline Risk assessment & $3(3)$ \\
\hline Genetics & $3(3)$ \\
\hline Epidemiology/statistics & $3(3)$ \\
\hline Other & $5(5)$ \\
\hline \multicolumn{2}{|l|}{ Previous connection with the tobacco industry } \\
\hline CIAR grantee & $53(50)$ \\
\hline CIAR listed peer reviewer & $22(21)$ \\
\hline CIAR grant applicant & $3(3)$ \\
\hline CIAR funded project co-author & $5(5)$ \\
\hline Other tobacco industry funding relationship & 5 (5) \\
\hline No previous tobacco industry connection & $17(15)$ \\
\hline \multicolumn{2}{|c|}{$\begin{array}{l}{ }^{\star} \text { Four of whom have PhD. } \\
\text { †One is a consultant to the US Environmental Protection } \\
\text { Agency (EPA). } \\
\text { ‡Includes three people from US National Institutes of Health } \\
\text { and three people from Oak Ridge National Laboratory. } \\
\text { gOnly one working in nicotine chemistry/metabolism. } \\
\text { I Three are retired PM scientists. } \\
\text { CIAR, Center for Indoor Air Research; PM, Philip Morris. }\end{array}$} \\
\hline
\end{tabular}

with each other and these papers were counted twice. Some reviewers have also written for peer reviewed journals outside of Medline's purview).

Table 1 describes the peer reviewers' profiles. Forty four per cent of the reviewers are experts in the field of indoor and outdoor air pollutant and air quality research, but only one peer reviewer is an expert in nicotine metabolism and chemistry. Fifty per cent of the reviewers have previously received CIAR grants and only $15 \%$ have no previous funding relationship with the tobacco industry, as ascertained through a search of the tobacco

Table 2 Peer reviewers'Medline indexed publications

\begin{tabular}{|c|c|}
\hline Characteristics & Number \\
\hline Peer reviewers with Medline publications & $94^{\star}(90 \%)$ \\
\hline $\begin{array}{l}\text { Total number of Medline publications } \\
\text { Range } \\
\text { Median } \\
\text { Interquartile range }\end{array}$ & $\begin{array}{l}4502 \\
0-223 \\
28 \\
7-55\end{array}$ \\
\hline Peer reviewers' total number of tobacco related publications $\dagger$ in Medline & $298(7 \%)$ \\
\hline $\begin{array}{l}\text { Total number of peer reviewers with Medline publications with zero tobacco } \\
\text { related publications }\end{array}$ & $48(51 \%)$ \\
\hline $\begin{array}{l}\text { Number of peer reviewers who have } 10 \% \text { or more of total Medline } \\
\text { publications in tobacco related topic }\end{array}$ & $20(19 \%)$ \\
\hline $\begin{array}{l}\text { Ratio of tobacco related articles to total Medline indexed articles } \\
\text { Range } \\
\text { Median } \\
\text { Interquartile range }\end{array}$ & $\begin{array}{l}0-100 \% \\
0 \\
0-8 \%\end{array}$ \\
\hline
\end{tabular}

industry documents available on the internet. ${ }^{21} 25-30$

Table 2 describes the publication record of the peer reviewers in Medline. Publication dates extend from the 1950 s to the present, but the majority fall within the past 15 years. Ninety per cent $(n=94)$ of the reviewers had papers published on Medline indexed journals, with a total of 4502 publications. The total number of tobacco related publications (determined by using the MeSH terms described earlier) is $298,7 \%$ of the total Medline publications. Forty eight $(51 \%)$ of the peer reviewers with publications indexed on Medline had no tobacco related publications and only $20(19 \%)$ of the 94 had published $10 \%$ or more of their papers on topics related to tobacco and smoking. By comparison, the six members of the SAB have an average of 191 articles on Medline (range 94-366), with four having $10 \%$ or more on tobacco related topics (range 1-98).

This analysis shows that the PMERP has many similarities with the structure of CIAR. In its day CIAR was not an independent and objective enterprise. CIAR's structure, and its sponsored studies and publications, were used aggressively by the tobacco industry to counteract and subvert the conclusions of the IARC study on second hand smoke, ${ }^{9}$ to provide evidence in regulatory agency hearings, and to battle legislative efforts to pass clean indoor air measures. ${ }^{31}$

As Barnes and Bero have shown, ${ }^{31}$ CIAR funded two types of projects: peer reviewed and special reviewed. The CIAR review process was used to serve the industry's political and legal interests, with peer review projects serving to "enhance its [tobacco industry] credibility" and to "divert attention of ETS as an indoor air pollutant". ${ }^{31}$ Projects approved directly by tobacco company executives through the special review process were more likely to produce exculpatory evidence on second hand smoke that could then be used by the industry in litigious and legislative efforts against public smoking bans.

Since the review structure for the PMERP gives final say on funding decisions to the unidentified "Philip Morris scientific research review committee" and not to the SAB, the same biased outcome may occur. In addition, CIAR was known to use its sponsored symposia to produce publications favouring the industry's position. ${ }^{32-35}$ It is unknown if PMERP sponsored special projects, workshops, and conferences will serve the same purposes, but it is important to note that, in the past, industry academic sponsorship has often translated into industry biased science. ${ }^{36}{ }^{37}$

While we do not know which peer reviewers will ultimately be used, the proposed reviewers' relative lack of expertise in tobacco research, as ascertained by the Medline search, is also not reassuring.

We caution here that a scientist's past affiliation with the CIAR or with the new PMREP does not necessarily mean that the individual is openly, secretly or even naively pro-tobacco, as was often the case in the example of 
"Operation Whitecoat." ${ }^{38}{ }^{39}$ For instance, when US Congress staff polled nine members of the CIAR science advisory board in 1994, six of the seven respondents agreed that environmental tobacco smoke was a serious threat to children, and five agreed that it was a pulmonary carcinogen. ${ }^{40}$ Since the release of the request for applications, Essential Action, a nongovernmental organisation (NGO), has sponsored a letter writing campaign to pressure peer reviewers to have their names withdrawn from the list. Approximately $15 \%$ of the reviewers have agreed to Essential Action's request. ${ }^{41}$ Scientists accepting tobacco industry funding must consider the ethics of their actions. There is no evidence that PM will do anything other than continue its practise of attempting to establish credibility and legitimacy through the utilisation of outside scientists and institutions, a strategy also practised by British American Tobacco. ${ }^{42}$

In the wake of CIAR's extinction, PM has shown apparent concern with the continuity of its programmes, and is interested in pursuing its partnerships with academic institutions. While the MSA provided for the dissolution of CIAR, it did not bar the possibility of reconstitution under a new name, as it did specifically with CTR. ${ }^{1}$ In fact, in March of 1999, PM was apparently considering a "Proposal for formulation of a corporation to support indoor air research", with a structure similar to that of the CIAR. ${ }^{24} 43-48$ While we do not know if PM will create this non-profit research corporation, it is clear that the mission and objectives of PMERP, and that of its "manager", the Research management group, are intended to serve the same dual purpose of establishing partnerships and gaining scientific credibility.

Our review of the PMERP suggests that it represents the continuation of industry sponsored research through a structure that resembles the CIAR. We can legitimately question whether tobacco industry science will be converted to tobacco industry marketing, keeping "controversy alive" and thus continuing to threaten public health. We will not know PMERP's true impact until the research projects are approved, conducted and published in peer reviewed journals but, in the meantime, we can urge scientific and professional journals to expand their funding disclosure policies, so it will be possible to monitor the research that PM is sponsoring. We also urge granting agencies, unencumbered by the tobacco industry's burdensome motives, to continue to support and expand research programmes that respect the public health mandate to learn absolutely everything that can be known about tobacco smoking and health.

NORBERT HIRSCHHORN STELLA AGUINAGA BIALOUS STAN SHATENSTEIN

Correspondence to: Dr Norbert Hirschhorn, 1044 Chapel Street, Apartment 502, New Haven, CT 06510, USA; bertzpoet@yahoo.com

Contributors: Norbert Hirschhorn, Stella Aguinaga Bialous, and Stan Shatenstein analysed peer reviewers' profiles and and Stan Shatenstein analysed peer reviewers' profiles and Hamann analysed peer reviewers' profiles.
1 Master Settlement Agreement; 1998. www.naag.org/ tobaccopublic/library.cfm

2 WSA "Reasons to Be". Philip Morris. Accessed December 2000. Bates 2060565058/5059 www.pmdocs.com

3 Reif H. (Comments to Robin Kinser on WSA's draft project list). Philip Morris. April 19, 1999 Accessed December 2000. Bates $2064716844 ; 45 / 6856$ www.pmdocs.com

4 WSA Strategic Plan - Draft December 1998. Philip Morris. Accessed January 2001. Bates 2064716945/6951 www.pmdocs.com

5 Action on Smoking and Health UK. Tobacco explained: the truth about the tobacco industry ... in its own words. London: ASH-UK, 1998:9.

6 Cummings M, Sciandra R, Gingrass A, et al. What scientists funded by the tobacco industry believe about the hazards of cigarette smoking. Am f Public Health 1991;81:894-96.

7 Repace J, Lowrey A. An enforceable indoor air quality standard for environmental tobacco smoke in the workplace. Risk Analysis 1993;13:463-75.

8 Repace J, Jinot J, Bayard S, et al. Air nicotine and saliva cotinine as indicators of passive smoking exposure and risk. Risk Analysis 1998;18:71-83.

9 Ong E, Glantz S. Tobacco industry efforts subverting International Agency for Research on Cancer's second-hand national Agency for Research on Can

10 deBethizy J. Comments on: Environmental tobacco smoke: a guide to workplace smoking policies [Draft] EPA 400/690/004. Company RJRT. October 1990. Accessed February 2001. Bates $2026131624 / 1635$ www.pmdocs.com

11 Nelson P. Before the Occupational Safety and Health Administration Proposed rule on indoor air quality, Docket H-122: Comments on the use of nicotine as an environmental tobacco smoke biomarker. Company RJRT. April 5, 1994 Washington, DC. Accessed January 2001. Bates 2029044993/5036 www.pmdocs.com

12 Tobacco Issues: Philip Morris USA; 2000. www. philipmorrisusa.com

13 Committee of Experts on Tobacco Industry Documents. Tobacco company strategies to undermine tobacco control activities at the World Health Organization. Geneva: WHO, 2000:260.

14 Jha P, Chaloupka F, eds. Tobacco control in developing countries. Oxford University Press, 2000.

15 Institute of Medicine. Control of cardiovascular disease in developing countries: research, development, and institutional strengthening. Institute of Medicine, 1998.

16 World Health Organization. The World Health Report 1999: making a difference. Geneva: WHO, 1999:121.

17 Satcher D. Why we need an international agreement on tobacco control. Am F Public Health 2001;91:191-93.

18 National Cancer Institute. Tobacco research implementation plan. Priorities for tobacco research beyond the year 2000. Bethesda, Maryland: National Institutes of Health, 1998.

19 Hirschhorn N. Shameful science: four decades of the German tobacco industry's hidden research on smoking and health. Tobacco Control 2000;9:242-7.

20 Center for Indoor Air Research. 1998 Research agenda request for applications. CIAR. January 1998 Linthicum, Maryland. Accessed on November 2000. Bates 2063813598A/3630 www.pmdocs.com

21 Center for Indoor Air Research. Publications resulting from CIAR supported research, December 1995. CIAR. Linthicum, Maryland. Accessed December 2000. Bates 2061824826/4860 www.pmdocs.com

22 Rylander R, Lebowitz M. Letter of invitation. January 13, 1989 Accessed January 2001. Bates 2021006002/6003 www.pmdocs.com

23 Center for Indoor Air Research. Interim report to CIAR. Not for distribution. Contract number 90-003. CIAR. Linthicum, Maryland. Accessed January 2001. Bates 2023525088/5179 www.pmdocs.com

24 Lipowicz P. Memo to Cathy Ellis. Subject: proposal for formation of corporation to support indoor air research. Comments by Helmut REIF in bold italics. Philip Morris. Accessed December 2000. Bates 2063871374/1380 www.pmdocs.com

25 Center for Indoor Air Research. Supported studies, July 1992. CIAR. Linthicum, Maryland. Accessed December 2000. Bates 2025472045/2060 www.pmdocs.com

26 The Council for Tobacco Research USA Inc. Active CTR grantees as of July 1, 1998. CTR. Accessed December 2000. Bates 2060571189/1216 www.pmdocs.com

27 Center for Indoor Air Research. CIAR funded research as of March 1998 - project status report. CIAR. Linthicum, Maryland. Accessed December 2000. Bates 2063813811/ 3819 www.pmdocs.com

28 Center for Indoor Air Research. Publications resulting from CIAR Supported Research, May 1995. CIAR. Linthicum, Maryland. Accessed December 2000. Bates 2060546785/ 6803 www.pmdocs.com

29 Center for Indoor Air Research. Publications resulting from CIAR supported research, January 1999. CIAR. Linthicum, Maryland. Accessed December 2000. Bates 2063813820/3837 www.pmdocs.com

30 Reif $\mathrm{H}$. Research category, 1998 Funding cycle assessment by scientific affairs PM Europe, Helmut Reif. Philip Morris Europe. Accessed December 2000. Bates 2063596699/ 6722 www.pmdocs.com

31 Barnes D, Bero L. Industry-funded research and conflict of interest: an analysis of research sponsored by the tobacco Health Politic Policy Law 1996;21:515-42. 
32 Bero L, Glantz S, Rennie D. Publication bias and public health policy on environmental tobacco smoke. $¥ A M A$ health policy on

33 Bero L, Galbraith A, Rennie D. Sponsored symposia on environmental tobacco smoke. $\mathscr{f} A M A$ 1994;271:612-17.

34 Barnes D, Bero L. Why review articles on the health effects of passive smoking reach different conclusions. $\mathscr{F} A M A$ 1998;279:1566-70

35 Barnes D, Bero L. Scientific quality of original research articles on environmental tobacco smoke. Tobacco Contro 1997;6:19-26.

36 Non-Smokers' Rights Association. The Fraser Institute: economic think tank or front for the tobacco industry? Ottawa, Canada: Non-Smokers' Rights Association; 1999:20

37 Louw L. Tobacco policy: a matter of principle. Cape Town, South Africa: Free Market Foundation.

38 Proposal for the Organisation of the Whitecoat Project. Philip Morris Accessed February 2001 Philip Morris. Accesse pdfs/2501474262.pdf

39 Covington \& Burling. Report on the European Consultancy Programme. Philip Morris. London. Accessed February Programme. Philip Morris. London. Accessed February 2001 Bates 2500048956/8969 Memorandum http://

40 The survey of the Science Advisory Board of the Center for Indoor Air Research by Majority Staff, Health and the Environment Subcommittee Commerce, Washington, DC. Accessed December 2000. Bates 2044436543/6549, 54 www.pmdocs.com
41 White A. Industry funding of scientists: Essential Action; 2001

42 Chapman S, Shatenstein S. The ethics of the cash register: taking tobacco research dollars. Tobacco Control 2001; 10:1-2.

43 Lipowicz P. Memo to Ellis, Cathy L. (WSA) Re: Process for forming new corporation. Philip Morris. March 24, 1999 Accessed February 2001. Bates 2063871386 www.pmdocs.com

44 Lipowicz P. Memo to McAlpin, Loreen FW Subject: Proposal 11 March 1999, IAQ-Corporation. Philip Morris. March 17, 1999 Accessed February 2001. Bates 2063871382 www.pmdocs.com

45 Kassman A. Memo to McAlpin, Loreen Re: Proposal for SRRC. Philip Morris. March 16, 1999 Accessed February 2001. Bates 2063871381 www.pmdocs.com

46 Walk R. Memo to Peter Lipowicz. Subject: review of "Proposal for formation of corporation to support indoor air research" dated March 11, 1999. Philip Morris. Accessed February 2001. Bates 2063871372/1373 www.pmdocs.com

47 Beane T. Memo to McAlpin, Loreen Re: Proposal for SRRC. Philip Morris. March 17, 1999 Accessed February 2001. Bates 2063871383 www.pmdocs.com

48 Cox R. Memo to McAlpin, Loreen Re: Proposal for SRRC. Philip Morris. March 17, 1999 Accessed February 2001. Bates 2063871384 www.pmdocs.com

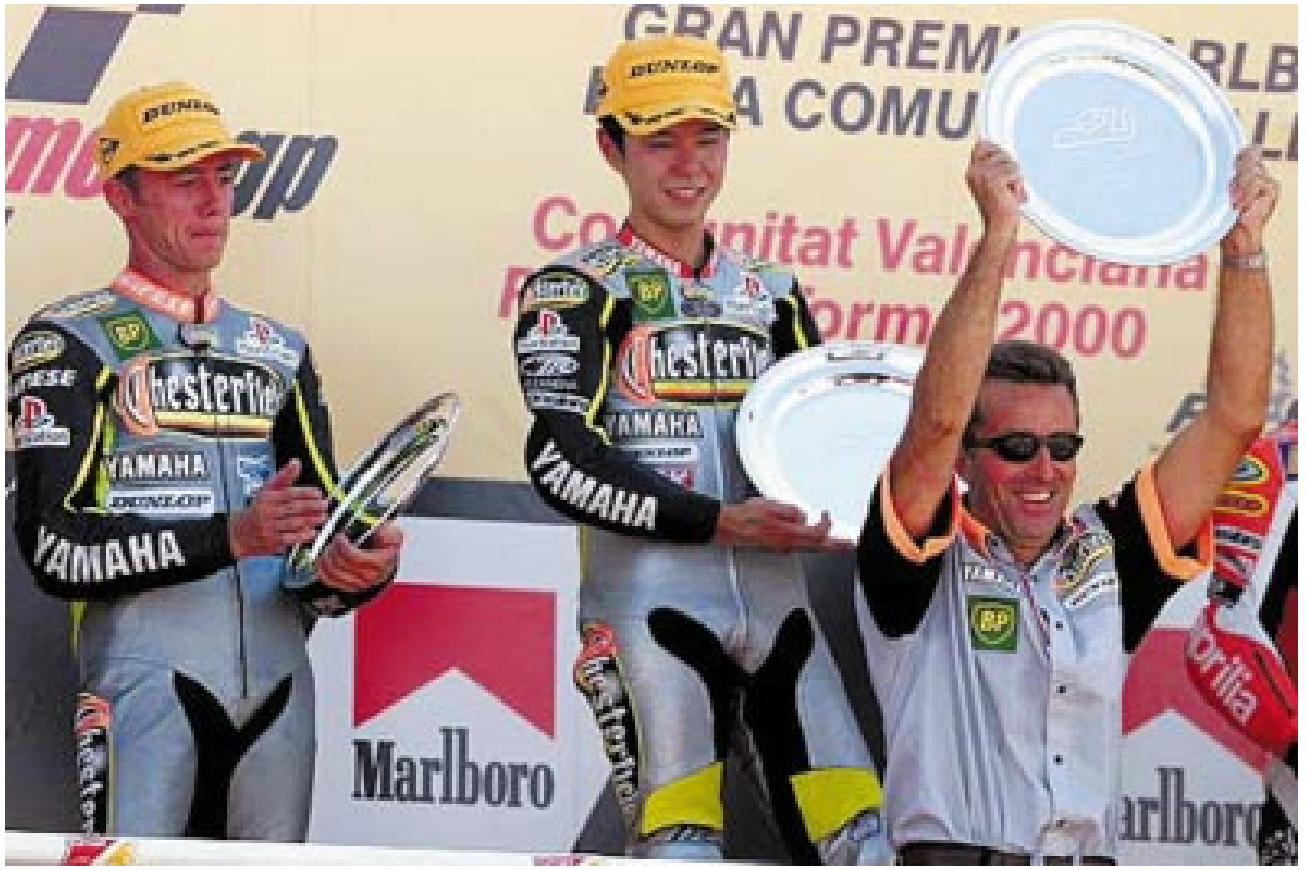

The Chesterfield Yamaha grand prix motorcycling team happy at their latest efforts to advertise Chesterfield to the world's adult smokers, and Play Station (see their upper sleeves) to the world's children. The idea is that children selectively perceive the Play Station ads, but not the Chesterfield ads. Makes sense, huh? 